\title{
Serviço de informação e assistência tecnológica para o segmento agroindustrial de alimentos*
}

\section{Rejane Gontow}

\section{Resumo}

A necessidade de desenvolvimento econômico imposta pela conjuntura atual vem exigir alta demanda de serviços especializados que se proponham a oferecer ao mercado valor agregado a partir da matéria-prima que representa a informação. É de vital importância a possibilidade de assessoria, consultoria e capacitação que este serviço pode oferecer a fim de garantir a adoção das recomendações propostas e, fundamentalmente, obter resultados importantes para o cliente e o mercado. Indicadores de desempenho devem ser estabelecidos como ferramenta crítica de gestão, e atenção muito especial deve ser dada à definição quanto ao perfil do gerente de um serviço desse porte. Recomenda-se que seu gerenciamento seja delegado a um empresário de informação, que possa imprimir ao serviço uma capacidade multidisciplinar, na busca da excelência do desempenho.

Palavras-chave

Informação tecnológica; Serviços de informação; Agroindústria de alimentos; Gestão da informação.

\section{DEMANDA/PROBLEMA E SUA IMPORTÂNCIA}

A filosofia de um serviço de informação e assistência tecnológica à agroindústria é a de buscar o desenvolvimento dos setores envolvidos, mediante a capacitação à modernidade, tecnologia, produtividade e competitividade.

A nova realidade dos anos 90 levou as empresas industriais a se voltarem para questões como controle de poluição industrial, qualidade, eficiência gerencial, tendo em vista a própria amplitude do ambiente externo da organização, decorrente da globalização da economia mundial. Esse contexto caracterizou-se por uma visível aceleração, uma competição baseada no tempo, com a presença de ciclos menores de vida para os produtos, lançamentos cada vez mais freqüentes de novos modelos, assim como de sistemas logísticos para acelerar o fluxo de materiais e otimizar o fluxo desde a matéria-prima até o produto acabado'.

Além do fator primordial na área de redução de prazos, custos dos processos e aumento de qualidade, as novas tendências da tecnologia da informação passaram a ser para muitas empresas uma ferramenta de aumento de receita. Transformaram-se num fator de diferenciação, o que ocasionou o lançamento de inúmeros serviços adicionais no intuito de tornar o produto/serviço mais atraente ao cliente. Foi o que realizaram os bancos, ao oferecerem informações sobre saldo de conta-corrente, investimentos, saques de dinheiro

* Parte da proposta elaborada, pela autora, para a Embrapa/CTAA, revisada e alterada. por telefone. Estas instituições identificaram que o principal valor agregado ao seu produto era a variável "tempo do cliente".

Entretanto, conforme a $\mathrm{Abia}^{2}$, o conceito de qualidade assegurada, importante e nos dias de hoje imprescindível para otimizar as inter-relações entre fornecedores e clientes, ainda não se faz presente de forma satisfatória no âmbito das indústrias fornecedoras do sistema agroindustrial, fruto, principalmente, da ausência ou desestruturação de redes de informação (muito embora o contexto comece a exigir maior número de variáveis, com inter-relações cada vez mais complexas, nas tomadas de decisão dos empresários, requerendo um número cada vez maior de informações).

Ainda segundo a Abia, para corroborar com este quadro, poucos são os esforços direcionados na formação de núcleos de capacitação e de currículos básicos e facultativos por parte das inúmeras entidades de ensino correlacionadas com o sistema em todos os seus níveis, apesar de ser muito grande a demanda para cursos e seminários ao nível executivo e gerencial.

O mais preocupante, no entanto, é que - Diagnóstico e tendências nacionais e internacionais da qualidade e produtividade do setor, elaborado pela $\mathrm{Abia}^{3}$ em 1992, já apontava para o fato de que, "sem providências deste tipo, só a longo prazo surgirá no Brasil uma classe de empresários modernos, sintonizados com os avanços tecnológicos, administrativos e mercadológicos do mundo atual". 
Uma nova postura gerencial começa a ser exigida, por uma confluência de fatores relacionados à política externa, ao desenvolvimento de novas tecnologias e ao valor e uso da informação, e a informação começa a ser percebida como insumo do processo industrial e, conseqüentemente, a fazer parte dos custos operacionais das empresas.

Ao mesmo tempo, a informação passa a representar o meio de sincronizar as diversas funções, processos e setores de uma empresa, em busca de seus objetivos; não se trata aqui apenas de processamento de dados mediante 0 uso de computadores, e sim de se prover o conhecimento e orientações necessários a cada função, a cada processo da empresa, no momento certo e na precisão requerida, visando a contribuir com o fim da informalidade na gestão em geral ${ }^{4}$.

Definitivamente, os anos de ineficiência, mascarados por repasse de preços para os bens produzidos e ganhos fáceis disfarçados na ciranda inflacionária, deram lugar à economia globalizada, na qual a competição é feroz e só sobrevive quem tem controle seguro sobre a forma como opera. Tanto é assim, que os sistemas de gestão empresarial (ERP), ou Enterprise Resources Planning, deixaram de ser prerrogativas de grandes companhias, passando a ser vitais até mesmo para pequenos empresários ${ }^{5}$.

Além disso, a sociedade sofre a mais profunda de suas crises, e pelo menos 9 dos 30 milhões de famílias vivem em um estado de extrema carência alimentar, o que já caracteriza, por si só, a necessidade de esforços dirigidos, em caráter emergencial, para a recuperação e revalorização da atividade agrícola e agroindustrial.

Muito embora Toffler considere que é possível resolver os problemas de atendimento às necessidades básicas da população, de produção de alimentos, de distribuição de renda e de erradicação da pobreza absoluta, optando pelo novo conceito de uma sociedade baseada em informação, a oferta de serviços de informação tecnológica no Brasil ainda é muito pouco efetiva e os esforços insuficientes diante de um elenco enorme de necessidades sociais não atendidas ${ }^{6}$.
Um serviço de informação e assistência tecnológica para as indústrias envolvidas na cadeia agroalimentar teria como objetivo, além de dar sustento à demanda da produção agropecuária, propiciando longa vida aos produtos processados, permitir maior aproveitamento do que é produzido, o que é indispensável para que se possa obter um barateamento dos gêneros alimentícios em geral.

Como a agroindústria de alimentos é extremamente diversificada e heterogênea, tanto em produtos, processos e matérias-primas, quanto em necessidades e demandas, existe uma limitação natural da capacidade técnica instalada nas instituições de pesquisa, em geral, para atender a todo esse universo. Estas instituições, conseqüentemente, precisam mudar de postura, ou seja, não podem e não devem mais atuar dentro de um conceito de "exclusividade", fechadas em si mesmas. Amplia-se, infinitamente, a necessidade de se estabelecerem alianças estratégicas, e há uma tendência em se recorrer à terceirização, na busca constante do atendimento às exigências cada vez mais específicas do mercado, inclusive como fator de sobrevivência.

Existe um mercado potencial atrativo, e muitos projetos têm alcançado êxito nos seus resultados. Falta, entretanto, dar maior valor agregado aos serviços prestados, com uma adequada visão do negócio em si, definindo não só as estratégias de comercialização que visam a assegurar o desenvolvimento independente destes serviços, como também os mecanismos de interação na busca de soluções para os problemas demandados.

Um dos aspectos que não se pode deixar de considerar é a própria revolução dos sistemas de informação com a Internet, que permitiu uma integração de indivíduos, independentemente de suas instituições ou países.

Apesar de poder contar com boa formação de especialistas em ciência da informação, é importante estimular o desenvolvimento de empresários de informação (infopreneurs) para o gerenciamento de um serviço de caráter multidisciplinar, que não pode mais ser visto como "feudo" e que envolve tecnologias, negócios, economia e sistemas, para garantir seu efetivo desempenho.

\section{OBJETIVOS}

- Fomentar e apoiar o desenvolvimento industrial e tecnológico dos segmentos envolvidos na cadeia agroalimentar.

- Facilitar a transferência de tecnologia com produtos de informação, consultoria, assistência técnica e capacitação.

- Integrar recursos de organizações nacionais e internacionais para a solução de problemas.

\section{REVISÃO DE LITERATURA}

É irreversível o processo de modernização da agricultura, necessitando e absorvendo cada vez mais tecnologias, como é irreversível a interdependência entre insumo-agricultor-indústrias de processamento e distribuição que caracterizam o complexo agroindustrial $^{7}$. Tanto assim, que a integração entre atividades, desde a produção até o consumidor final, tem movimentado bilhões de dólares no mundo mais desenvolvido e colocado a informação como elemento central do processo, devido, principalmente, ao grande número de produtos comercializados ${ }^{8}$. Além disso, o enfoque sistêmico começa a exigir do trabalhador habilidade para operar em ambiente difuso e mutante, tomar decisões e assumir responsabilidades, assim como trabalhar de forma interdisciplinar, introduzindo conotações diferentes às relações de trabalho. Conseqüentemente, o domínio e o gerenciamento do fluxo de informações passam a ser um dos principais insumos de produção.

A eficiência do complexo começa ser percebida como importante, não só para alcançar altos índices de competitividade, mas sim porque é a única forma de baratear o nosso alimento internamente, com vistas à melhoria da qualidade de vida. "É a condição para a existência de uma sociedade organizada, capaz de imprimir dinâmica a seu processo de desenvolvimento e de retomar o crescimento pela demanda sustentada que o padrão alimentar permite assegurar"9. 
A inclusão da informação, de forma sistemática, nos planos, programas e ações do setor de ciência e tecnologia, nos últimos anos, é testemunho de que essa é considerada um insumo essencial para a pesquisa científica e tecnológica.

Porém, as conseqüências do processo anterior de descontinuidade de formulação de uma política de investimento foram de um comprometimento da eficiência do sistema de informação, tanto científico quanto técnico, que resultou em serviços muito aquém do desejável, em número e qualidade ${ }^{10}$.

As empresas, ao contratar serviços para apoio ao seu desenvolvimento tecnológico, exigem uma solução completa e contínua, a fim de minimizar os riscos de insucesso e diminuir custos do processo, o que justifica a importância da implantação de serviços de informação especializados que estabeleçam, inclusive, um conjunto de padrões comerciais próprios da economia da informação, visando fundamentalmente a fornecer informações melhores, para mais usuários, a custo mais baixos, e aumentar o valor da informação, transformando dados em dinheiro ${ }^{11,12}$. Não bastam, no entanto, equipamentos e acessos a fontes de informação. São fundamentalmente essenciais metodologias, ferramentas e recursos humanos.

Os sistemas de informação que existem desde os anos 60 já foram objeto de crítica em função das suas limitações no que tange ao atendimento às necessidades dos usuários e à insuficiente capacidade de decisão que oferecem. Tanto assim, que várias propostas têm sido formuladas para que não se limitem ao processamento e à recuperação da informação ${ }^{13}$.

Canhos e Canhos ${ }^{14}$, referindo-se à informação ambiental em termos de dados biológicos, conseguem tornar mais perceptíveis estes limites, quando afirmam que: "Temos a necessidade primordial de mudanças de paradigmas das coleções biológicas. As coleções biológicas (zoológicas, herbários, microbiológicas...) têm sido repositórios estáticos de informação, catalogando espécimens e realizando atividades de análise sistemática (...). A coleta é fei- ta como se a natureza fosse segmentada (...). A natureza não vive assim, no entanto insistimos em organizar e disseminar a informação como feudos. A pesquisa e a conservação da biodiversidade requerem um tratamento multidisciplinar".

"O Programa de Apoio à Capacitação Tecnológica da Indústria (PACTI), que define a estratégia da política industrial para a melhoria e aumento da produção e comercialização de bens e serviços, considera a consolidação de redes de informação tecnológica como ação fundamental para a criação e o fortalecimento das condições externas necessárias à capacitação tecnológica. Nesse contexto, entende-se capacitação tecnológica como a capacidade das empresas em desenvolver inovações, bem como selecionar, licenciar, absorver, adaptar, aperfeiçoar e difundir tecnologias nacionais ou importadas." Tanto assim, que foi aprovado pela Comissão Permanente do PACTI o documento "Ação Planejada em Informação Tecnológica", com o objetivo de desenvolver e apoiar produtos e serviços de informação de acordo com o PACTI e consolidar e expandir os centros, núcleos, serviços e redes de informação tecnológica ${ }^{15}$.

A ausência de um enfoque voltado para as realidades sócio-econômicas, políticas e culturais, no entanto, pode ter sido, até o momento, um empecilho ao desenvolvimento destas redes, uma vez que seu funcionamento decorre de necessidades sociais determinadas, formadas por características do indivíduo e circunstâncias do meio ambiente. É preciso começar a identificar e analisar as barreiras que interferem no fluxo da informação, para que se possa compreender e melhorar o processo de transferência de informação, aumentando o êxito de todo o processo. Para tanto, é preciso levar em consideração o valor de uso da informação que deve ser medido, basicamente, por meio de três aspectos: pertinência, utilidade e adequação da informação elaborada que, certamente, deve ser compatível com a capacidade do demandador ${ }^{16}$.
O papel dos serviços de informação é, cada vez mais nitidamente, o de atender a expectativas novas e diversificadas, tendo a habilidade para fornecer a informação necessária com muita precisão. Para sobreviver na era da informação, diz Evans apud Popcorn ${ }^{17}$, você tem de ser preciso, procurando conquistar a fidelidade dos clientes como forma de preservá-los. Deste modo, é fundamental possuir mais do que competência técnica para interpretar as necessidades e também o uso da informação de acordo com os muitos sistemas que afetam cada aspecto do trabalho de um empresário, assim como para analisar os mecanismos de interação entre os vários elementos que os compõem e os efeitos que as mudanças de um elemento podem trazer ao sistema como um todo.

Os sistemas que afetam o usuário formam um conjunto de círculos quase concêntricos, ao considerá-lo em relação à sua cultura, ao sistema político, ao grupo do qual ele faz parte, ao grupo de referência, ao colégio invisível, à organização formal, à equipe de trabaIho, a ele mesmo, ao sistema legal e econômico e ao sistema formal de informação (Paisley apud Coelho et alii.) $)^{18}$.

Sob o prisma do enfoque sistêmico, portanto, torna-se fundamentalmente inadequada a separação dos agentes das cadeias agroalimentares em setores estanques (primário, secundário e terciário), uma vez que, somente mediante este enfoque, pode-se perceber os diversos agentes como participantes de um mesmo empreendimento e, conseqüentemente, estabelecer políticas e estratégias de ação verdadeiramente efetivas ${ }^{19}$.

Este enfoque evidencia, com muita nitidez, a urgência da organização desses agentes e confere à informação o caráter de uma ferramenta estratégica. 


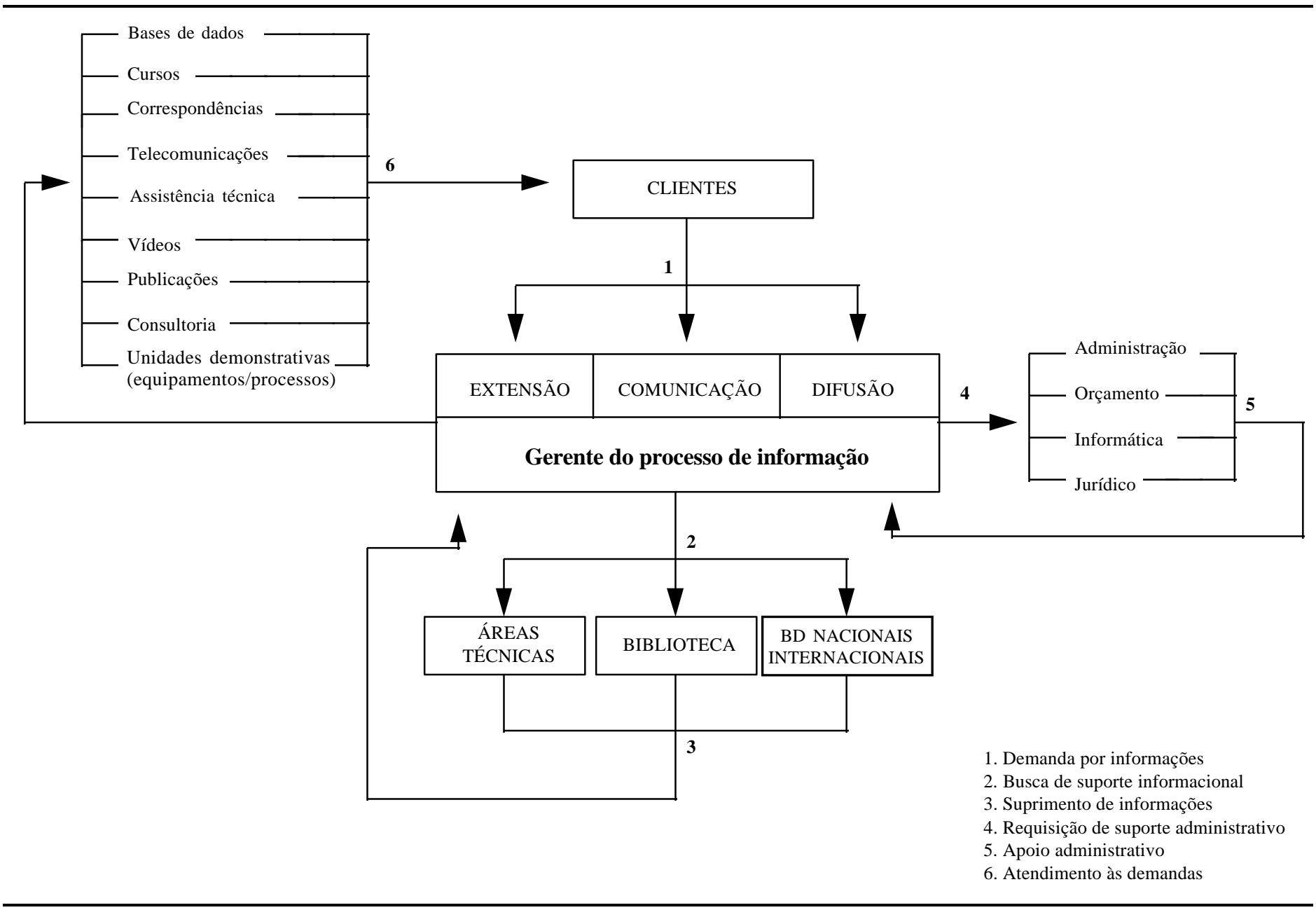

\section{COMENTÁRIOS, CONCLUSÕES E RECOMENDAÇÕES}

O papel estratégico da informação no cenário atual, como insumo à produção e gerenciamento dos recursos produtivos, sinaliza a importância da criação de serviços de informação e assistência tecnológica à agroindústria, pela possibilidade de exploração de fontes de informação e transferência de tecnologia que podem ser oferecidas.

Como o processo de modernização é irreversível e, para tanto, requer altos investimentos em capacitação, os resultados esperados são de um comprometimento absoluto com o processo, porém de uma forma menos verticalizada. Somente assim, estabelecendo maior interação entre a oferta e a demanda, serão capazes de oferecer, com a matéria-prima informação, o apoio necessário ao desenvolvimento dos setores envolvidos.
Para tal, é necessário que se crie, primordialmente, um ambiente propício para o desenvolvimento do serviço, dentro da própria instituição. Conforme pode ser percebido no fluxograma básico do processo de informação (figura 1), a gerência do processo depende, em primeira instância, do apoio logístico recebido dentro da instituição. O serviço não tem como se desenvolver, sem o estabelecimento de uma boa parceria interna, sem um bom conceito de integração.

Isto porque as parcerias internas envolvem a criação de uma rede de relacionamentos entre as unidades da organização, levando à melhor flexibilidade, prontidão de resposta e maior troca de conhecimentos ${ }^{20}$. O processo de informação, conseqüentemente, não mais pode ser percebido como restrito à área de informação (biblioteca), resultando em uma clara departamentalização, visto que envolve, entre outros, uma série de processos de apoio que podem incluir finanças e contabilidade, serviços jurídicos, administrativos e de secretaria, relações públicas e serviços de software (figura 1).

A Intranet ${ }^{21}$, neste cenário, pode ser uma excelente ferramenta para facilitar o compartilhamento de informações dentro da própria instituição e dinamizar, inclusive, o cumprimento de prazos. A Internet, por sua vez, ao abrir as portas para o mundo exterior, pode trazer muitos benefícios para a institutição como um todo, principalmente pela forma em que pode passar a interagir com os clientes. Neste contexto, podese ampliar o campo de ação, procurando estabelecer, por exemplo, melhor articulação/integração entre os serviços de informação tecnológica já existentes, como as redes do Serviço Brasileiro de Apoio às Micro e Pequenas Empresas (Sebrae), a rede de documentação da Confederação Nacional da Indústria (CNI), as Emater, o Senaitec, o Tecpar, o IPT, entre outros que atuam 
diretamente na prestação de produtos/ serviços de informação para a indústria. E, ainda mais, envolver, nesta integração/articulação, as indústrias de equipamentos, as organizações educacionais com diversos propósitos (como as escolas de desenho industrial), assim como inúmeros tipos de fornecedores, entre muitos outros elos da cadeia agroalimentar.

As parcerias externas favorecem a integração do núcleo de competência de uma organização com os pontos fortes da parceria, incrementando a capacitação global ${ }^{22}$. Visam, desta forma, a garantir a qualidade dos resultados, do ponto de vista dos clientes.

O fator heterogeneidade do complexo agroindustrial de alimentos e a necessidade de tratá-lo de forma sistêmica justificam os esforços que precisam ainda ser dirigidos no aprimoramento de serviços de apoio à agroindústria, principalmente quando o objetivo é a busca de soluções para os problemas demandados.

Acredita-se que existe ainda muito a percorrer no sentido de atender a expectativas de melhoria do processo global do negócio. São, então, aqui sugeridas algumas etapas consideradas primordiais para a estruturação de um serviço de informação, na busca constante da excelência do desempenho de suas atribuições:

- definição clara da missão: considerase a busca de soluções para os problemas demandados a mais compatível e, certamente, coerente com a missão institucional;
- desenvolvimento de um modelo de planejamento, acompanhamento e avaliação das atividades de transferência de informação;

- articulação com órgãos de fomento para a obtenção de recursos financeiros destinados às despesas com manutenção de equipamentos, treinamentos, despesas com comunicação, aquisição de equipamentos e material permanente, mão-de-obra, entre outros, no sentido de garantir o andamento das atividades propostas;

- identificação de parceiros e estabelecimento de contratos efetivos de parceria;

- treinamento do pessoal envolvido, para introdução de uma nova cultura ao serviço, principalmente no que se refere à visão do negócio em si;

- capacitação de pessoal em técnicas e metodologias de trabalho, como também no uso de tecnologias de transmissão, processamento e armazenamento de informações;

- desenvolvimento de um programa específico de treinamento em técnicas de vendas para que a equipe técnica seja capaz, entre muitos outros, de apresentar seus serviços, em suas características, vantagens e benefícios;

- definição do perfil dos profissionais envolvidos no serviço, tendo como base as metas a serem alcançadas;

- definição do perfil do gerente, tendo como base a versatilidade necessária para atuar em um ambiente multidisciplinar;
- estabelecimento de indicadores de desempenho como ferramenta crítica de gestão e de retroalimentação do serviço;

- adequação dos produtos/serviços às demandas do mercado, sem deixar de considerar o fator "ciclo de vida".

Em outras palavras, o serviço deve estar estruturado para oferecer informação de alta qualidade e obter total satisfação do cliente. As informações devem facilitar a comunicação, a tomada de decisão e a ação, levando em consideração, principalmente, o princípio de Pareto, segundo o qual $20 \%$ das informações contribuem diretamente para $80 \%$ das decisões de uma organização.

É essencial também levar em consideração o mesmo princípio quando da comercialização dos serviços, período em que $20 \%$ dos produtos são responsáveis por $80 \%$ das vendas e $20 \%$ dos clientes geram $80 \%$ da renda. Pode-se, assim, investir em marketing onde ele tenha seu maior impacto e traga o meIhor retorno.

Entendido desta maneira, o sucesso de um projeto deste porte reside, last but not least, em obter alto grau de comprometimento com o processo global do negócio, por parte da equipe envolvida. Somar-se-ia, ainda, uma disponibilização para as crescentes mudanças impostas pelo próprio mercado de informação, assim como permanente capacitação para atuar em um ambiente ao mesmo tempo complexo e competitivo. 


\section{REFERÊNCIAS BIBLIOGRÁFICAS}

\section{Information and technological assistance services for the agroindustry}

\author{
Abstract \\ The need for economical development, \\ imposed by the present conjuncture, results in \\ a demand for value-added and specialized \\ information services. Therefore, the \\ perspective of offering capacitation and \\ consulting services is of vital importance in \\ order to garantee the adoption of the \\ proposed recommendations and, essentially, \\ important results to the customers and to the \\ market. Performance indicators should be \\ established as a critical management tool and \\ a special attention should be given in defining \\ the manager's profile for this kind of service. \\ It is recommended that an information \\ manager assumes this task to give a \\ multiple-subject capacity to the service, in \\ order to search for the best performance.
}

\section{Keywords}

Technological information; Information services; Information; Agroindustry; Information management.
1. Vianna, M. C. de S. Tecnologia da informação e competitividade - uma visão econômica. Palestra proferida na Mesa-Redonda sobre Informação na Petrobrás. Rio de Janeiro, 1993.

2. ABIA. Programa Brasileiro de Qualidade e Produtividade. Subcomitê da Agroindústria de Alimentos. Diagnóstico e tendências nacionais e internacionais da qualidade e produtividade do setor. São Paulo, agosto de 1992.

3. Idem.

4. Moura, L.R. Informação: a essência da qualidade. Ciência da Informação, v.25, n.1, p.3642, jan./abr. 1996.

5. Gestão empresarial: a vez das pequenas empresas. Informática Hoje, v. 12, n.425, p.2026, 16 a 31/março, 1997. Caderno Especial.

6. Marcovitch, J. O novo contexto mundial, desafio tecnológico e a integração latino-americana. Revista de Administração, São Paulo, v.24, n.2, p.10, abr.jun. 1988.

7. Araujo, N.B. de. Reflexões sobre o complexo agroindustrial. In: Congresso Brasileiro de Economia e Sociologia Rural, 28. Florianópolis, SC., 22 a 27 de julho, 1990. Anais. Brasília, DF, SOBER, 1990. p.236257.

8. Sarmento, E.P. de M., Araújo, J.D. de. Os complexos agroindustriais e a pesquisa agropecuária: uma visão prospectiva. In: Congresso Brasileiro de Economia e Sociologia Rural, 28. Florianópolis, SC., 22 a 27 de julho, 1990. Anais. Brasília, DF, SOBER, 1990. p.196-206.

15. BRASIL. Ministério da Economia, Fazenda e Planejamento. Política Industrial e de Comércio Exterior PACTI: apoio à capacitação tecnológica da indústria. 2.ed. Brasília, MEFP, 1991. 43p. apud CARVALHO, M.C.R. de. Ação planejada em Informação Tecnológica. Ciência da Informação, v.21, n.1, p.147-148, maio/ago., 1992.

16. PETITDEMANGE, C. La maîtrise de la valeur: conception, développement. qualité et competitivité d'un produit. Paris: AFNOR, 1995., apud SANTOS, R.N.M. dos. Sistemas de Informações Estratégicas para a vitalidade da empresa. Ciência da Informação, v.25, n.1, p.12-14, jan./abril 1996.

17. EVANS, J.B., apud POPCORN, F. O relatório Popcorn: centenas de idéias de novos produtos, empreendimentos e novos mercados. Rio de Janeiro, Campus, 1993. 207p.

18. PAISLEY, W.J. Information needs and uses. In CUADRA, C.A., ed. Annual Review of Information Science and Technology. Chicago: Enyclopaedia Britannica, 1968. v.3, p.130, apud COELHO, B.A. de S., MAMFRIM, F., GONTOW, R. et al. Estudos de usuário e comunicação científica: relações implícitas e explícitas. Ciência da Informação, v.18, n.1, p.62-73, jan./jun. 1989.

19. ABAG. Associação Brasileira de Agrobusiness. Segurança Alimentar: uma abordagem de Agrobusiness. São Paulo, Abag, 1993.

20. Critérios de Excelência: o estado-da-arte da gestão para a excelência do desempenho. São Paulo, Fundação para o Prêmio Nacional da Qualidade, 1997. 73p.

21. AUGUSTO, A. 97, o Ano da Intranet. Byte Brasil, p.31-34, março 1997.

9. ABAG. Associação Brasileira de Agrobusiness. Segurança Alimentar: uma abordagem de Agrobusiness. São Paulo, Abag, 1993. p.26

10. TARAPANOFF, K. A política científica e tecnológica no Brasil: o papel do IBICT. Ciência da Informação, v.21, n.1, p.149158, maio/ago. 1992.

11. RAMOS, P.A.B. Um modelo integrado de informação e assistência tecnológica: o Senaitec. Ciência da Informação, v.21, n.1, p.137-139, maio/ago. 1992.

12. WEITZEN, H.S. O poder da informação: como transformar a informação que você domina em um negócio lucrativo. São Paulo: Makron, McGraw-Hill, 1991. p.78

13. THIOLLENT, M. Organização do trabalho intelectual e novas tecnologias do conhecimento. Ciência da Informação, v.21, n.1, p.110-114, maio/ago.1992.

14. CANHOS, D.A.L.; CANHOS, V.P. Disseminação de Informação: o uso da Internet. Campinas, Fundação Tropical de Pesquisas e Tecnologia "André Tosello/FEA/ Unicamp, 1977. No prelo.

\section{Rejane Gontow}

Consultora em banco de dados e sistemas de informação e ex-funcionária da Embrapa/CTAA. 